\title{
ESTRUCTURA Y USOS DE LA TIERRA EN LA SEVILLA PERIURBANA (1872-1948)
}

\author{
Antonio MARTIN GARCIA*
}

\section{INTRODUCCION}

La acotación cronológica referenciada no es en éste caso baladí, ni responde a la operatividad expositiva del discurso. Antes bien, es el resultado de condicionantes de fuentes y del empirismo de los hechos.

El incendio acaecido en 1906 en las instalaciones de la Delegación Provincial de Hacienda que supuso, entre otras, la desaparición del Archivo General, en el que se encontraba el Catastro de Ensenada, restringe notablemente la investigación del medio agrario secular hispalense. Tras laboriosa e ingente búsqueda en los restos del Archivo, por parte del personal encargado y por quien escribe, localizamos los Libros de Asientos correspondientes a 1872 y 1894, ambos completos. Ellos constituyen testigos privilegiados de la estructura de la propiedad agraria del término municipal de Sevilla, anterior al siglo $\mathrm{XX}$.

El límite temporal superior viene impuesto por dos acontecimientos relevantes. El primero, la realización en el trienio 1945-1948 del Catastro topográfico parcelario y, en segundo lugar, pero coincidiendo en el tiempo, concretamente 1946, la redacción y aprobación del primer Plan General de Ordenación Urbana de la Ciudad. Hasta esas fechas el crecimiento urbano extramuros de Sevilla había sido marginal y puntual (léase, entre otras, Bda. La Barzola; Nervión; Cerro del Aguila; Tiro de Línea...) y, superficialmente, el campo era dominante.

\footnotetext{
* Geógrafo. Gerencia Municipal de Urbanismo. Sevilla.
} 


\section{EL ULTIMO CUARTO DEL SIGLO XIX}

De los elementos que constituyen el binomio de la estructura agraria -propiedad y parcelación - éste último, por carencia en los Libros de Asientos y ausencia de apoyo gráfico (croquis o planos de los polígonos) del suelo rústico, en esas fechas, no podrá ser valorado.

Por otra parte, el no disponer, por los motivos aludidos (incendio de 1906), del Padrón de Contribuyentes de Riqueza de 1850, situado a caballo entre los dos procesos de desamortización de los bienes eclesiásticos, el de 1836, y civil, el de 1855, así como la inexistencia de estudios locales sobre la incidencia de tales hechos en la conformación de la propiedad agraria en el último cuarto del siglo XIX, nos condiciona a contrastar nuestras hipótesis con referencias parciales y de otra escala territorial.

Tras afirmar que el siglo XVIII no fue un período de conformación de abundantes latifundios M. ARTOLA ${ }^{1}$ al analizar el origen de ese modelo de explotación en Andalucía, señala que «la desamortización civil dió paso a la configuración de un nuevo latifundio, que como el del XVII, tiene como principal característica la extraordinaria dimensión de las nuevas fincas constituidas». A nivel provincial y por lo que se refiere a la desamortización eclesiástica, el mismo fenómeno es confirmado por A. $\mathrm{LAZO}^{2}$ : creciente desarrollo del latifundismo sevillano entre 1845 y 1931, aproximadamente; si bien se trata de un latifundismo más bien modesto pués son raros los adquirentes que llegan a poseer mil hectáreas en total, distribuídas entre varios términos municipales, con frecuencia. Quizás una excepción fue el caso estudiado por F. HERAN ${ }^{3}$, el de Ignacio Vázquez y Gutierrez, alcalde de Sevilla en 1840 que «se convirtió, bajo el reinado de Isabel II, en el contribuyente más importante dẹ la burguesía sevillana, únicamente aventajado por el duque de Osuna. La venta de los bienes nacionales (desamortización de 1836 y 1855) le permitió constituirse a lo largo del Guadalquivir un imperio territorial de más de seis mil (6.000) hectáreas».

Como ratifica en investigación reciente M. PARIAS ${ }^{4}$, en relación con la conformación decimonónica de la estructura de la propiedad sevillana, «el 11 por 100 de los compradores se hicieron con el 84,5 por 100 de la tierra en un

1. Artola, M. y otros (1978): El latifundio. Propiedad y explotación, ss. XVII-XX. Madrid. Ministerio de Agricultura.

2. Lazo, A. (1970): La desamortización de las tierras de la Iglesia en la provincia de Sevilla. Diputación Provincial.

3. Herán, F. (1980): Tierra y parentesco en el campo sevillano: la revolución agrícola del siglo $X I X$. Madrid. Ministerio de Agricultura.

4. Aproximación a la tipología del propietario agricola andaluz en el siglo XIX. Ocho casos de inversión sevillana. M. Parias. Rev. Estudios Andaluces, n. ${ }^{0} 10,1988$, pp. 137-176. 
tamaño superior a las 50 Has... la tendencia compradora obró categóricamente en beneficio de una concentración de la tierra en pocas manos. De éste modo, los dos fenómenos superpuestos (el de la compra de tierras en «unidades mayores» y el de la repetición de los sujetos compradores), indican sin reservas que en Sevilla, y a lo largo del siglo XIX, se consolidó una estructura concentrada de la propiedad agrícola».

La tendencia descrita se confirma a nivel local pues, en 1872, el campo sevillano estaba fuertemente concentrado en pocas manos. Tan sólo diecinueve grandes propietarios (de más de 100 Has.) disponían del 61,03 por 100 de la tierra. De cualquier forma, la distribución de la propiedad rústica de Sevilla era menos polarizada que la de Carmona en 1850, lo que hace que los valores del índice de Gini (0,74 y 0,84, respectivamente) exprese la apreciable diferencia.

En el transcurso del tiempo hasta 1894 , la estructura de la tenencia de la tierra permanece casi invariables en sus guarismos cuantitativos, hasta el punto de que sus valores son tan próximos que permitieron recogerlos en una sóla figura (gráfico I).

GRAFICO I. CURVA DE LORENZ 1872-1894

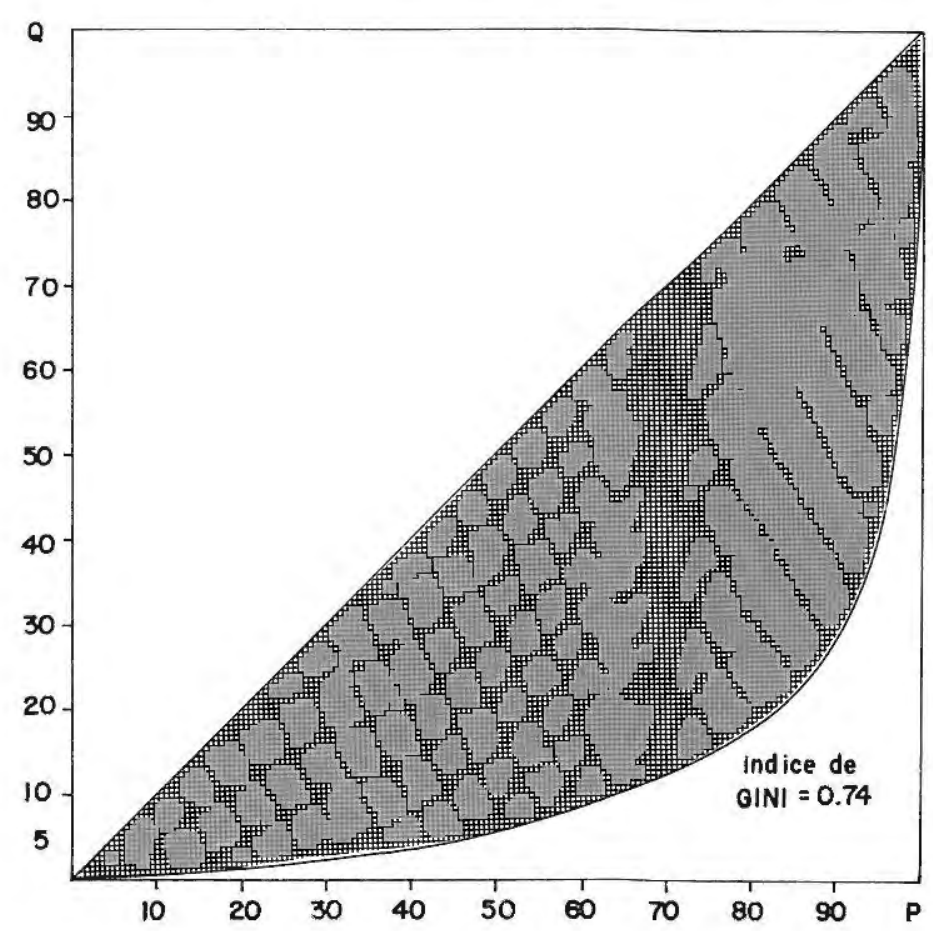


Los cambios producidos en la estructura agraria no son tanto de distribución (pues si bien el número de grandes propietarios crece un16 por 100 entre 1872 1894, la representación superficial de los mayores de 51 Has. sólo aumentan sus dominios en 1,43 por 100 de la tierra), cuanto de cambio de titularidad, al aparecer nuevos apellidos que vienen a reemplazar a los iniciales. Todo lo cual confirma, a éste nivel territorial, lo contrastado, a escala provincial, para la época, «en Sevilla, la especulación y la reventa de tierras, se habían convertido en un enorme juego fiduciario, que apenas dejaba un par de años las fincas en las mismas manos» ${ }^{5} \mathrm{y}$, a nivel andaluz, con lo defendido por A.M. BERNAL y M. ARTOLA ${ }^{6}$ en cuanto en el intervalo de 1855 a 1875 se produce un «descenso de la propiedad señorial y aumento de las propiedades de la nobleza secundaria y de la burguesía agraria».

Dentro de una propiedad mayoritariamente particular, el patrimonio público de tierra estaba representado por el Ayuntamiento con 275,23 Has. en 1872, que se veran reducidas a $128,67 \mathrm{Has}$, en 1894. La propiedad no laica se circunscribía a 286,20 Has. que poseía el Hospital de la Stma. Caridad, en la denominada Hacienda Carriles, actual Torreblanca.

CUADRO I

USOS DE LA TIERRA EN EL MUNICIPIO DE SEVILLA, 1872 Y 1894 (\%)

\begin{tabular}{|c|c|c|}
\hline & 1872 & 1894 \\
\hline Cereal & 49,09 & 54,91 \\
\hline Olivar & 14,12 & 15,40 \\
\hline Huerta y Fruta & 6,76 & 7,12 \\
\hline 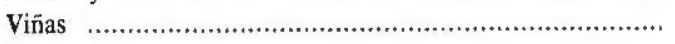 & 0,04 & 0,04 \\
\hline Pastos & 19,15 & 19,17 \\
\hline Ruedos & 10,84 & 2,78 \\
\hline Caseríos & - & 0,58 \\
\hline 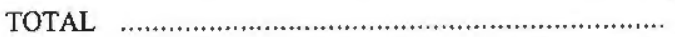 & 100 & 100 \\
\hline
\end{tabular}

En cuanto a los usos de la tierra, reseñados sus valores relativos en el cuadro I, hay que destacar, comparando las dos fechas de 1872 y 1894 , el avance de la superficie dedicada al olivar en detrimento de la tierra de labor, que detecta también J. CRUZ ${ }^{7}$, para el caso de Carmona en ese período.

Las notables carencias de los Libros de Asientos (estructura y cuantificación del parcelario rústico y ausencia de base gráfica, croquis, de las unidades administrativas - polígonos— del suelo agrario), ha podido ser parcialmerite

5. Lazo, A. op. cit., pág. 202.

6. El latifundio... op. cit. pág. 85.

7. Cruz, J. (1980): Propiedad y usos de la tierra en la Baja Andalucía. Carmona, siglos XVIII-XX. Madrid. Ministerio de Agricultura. 
subsanada por el trabajo de localización y recuperación, tras exhaustivo reportaje fotográfico y montaje, del plano del término municipal de Sevilla en 1889, de Alvarez Benavides ${ }^{8}$, a escala 1:20.000.

Exceptuada la uniforme distribución de los usos de huertas y ruedos, alrededor de la ciudad consolidada, en lo que más tarde será la primera periferia urbana por el este y sur del límite con el casco antiguo y, por la orilla izquierda del Guadalquivir, el futuro emplazamiento del barrio de Los Remedios y la Triana más reciente, la distribución espacial de los restantes usos mayoritarios (cereal-olivar-pastos) viene determianda por la propiedd de la tierra y la localizaciónde los suelos incultos. Esto es, la gran propiedad rústica asentada, sobre todo, a partir del arroyo Miraflores y de la vereda del Juncal como límites nor-oriental y sur-oriental, respectivamente, marca la presencia sobresaliente de la anterior trilogía.

Las áreas de pastos (dehesas, baldíos...) producto de condicionantes físicos del suelo, distribuidas desordenadamente por el término, tienen nombres propios y evocadores futuros de asentamientos marginales, autoconstruidos y, en el mejor de los casos, de usos no residenciales: baldío de Poco Aceite; baldío de la dehesa de Rojas; dehesa del Judio; de San Pablo; de Tablada...

La fuerte correlación, en el amplio arco extramuros N-NE y S-SE, entre usos agrarios y parcelación, ofrece un comportamiento opuesto en el territorio de la margen izquierda del Río (Vega de Triana, La Cartuja) que, en 1872, estaba prácticamente controlado su extensión en manos de dos grandes propietarios: D. a Amparo Lauraum y Muñoz, con 900,34 Has. en el Portón (Triana) y D. Ignacio Vázquez Gutierrez, con 271,89 Has. en el cortijo de Gambogaz (Cartuja). Es decir, en el último cuarto del siglo XIX, la Vega de TrianaLos Remedios era un suelo escasamente dividido en pequeñas suertes, poco compartimentado en su estructura física, dado el dominio absoluto de la gran propiedad y de los cultivos anuales.

En el sector meridional del término, las zonas de huertas se extienden desde la desembocadura del Miraflores y la ciudad consolidada; es aquí donde la propiedad está más dividida y la parcelación es más intensa. A partir del anterior curso de agua hacia el campo, el suelo rústico está muy concentrado en su tenencia y en amplios predios bajo una misma linde (dehesa de Tablada; cortijo de Maestre Escuela,...).

Asímismo, el que en 1894 aparezca un uso de caserio cuantificable (cuadro I) puede ser interpretado como un indicador del inicio de humanización o urbanización del campo. Esto es, de la proliferación residencial lejos de la Ciudad secular.

8. Cuyo ejemplar original, en grave proceso de deterioro, se encuentra en el Archivo Histórico Municipal. 


\section{EL AVANCE DEL CATASTRO DE 1933}

El evaluar la situación estructural del agro sevillano en los albores de la proclamación, por segunda vez, de la República en nuestro país, tiene el interés general de poder valorar el grado de incidencia que sobre la distribución de la propiedad rústica tuvo la alternancia de regímenes políticos tan intensos y contradictorios - república, monarquía, dictadura- que jalonan la vida pública y social de España en el último cuarto de siglo XIX y el primer tercio del $\mathrm{XX}$.

Para la sociedad local sevillana, que siempre vivió los acontecimientos históricos de forma especial, ésta fecha aumenta en significado por dos acontecimientos que, en principio, cabría esperar modificara la estructura de su campo, a saber: la celebración de la Exposición Iberoamericana de 1929 y la puesta en riego de la margen izquierda del Valle Inferior del Guadalquivir en 1921.

Pues bien, la comparación del dato que proporciona el índice de Gini para los años 1894 y 1933 confirma que, efectivamente, las transformaciones jurídicas (ha desaparecido la representación de la nobleza en la propiedad de la tierra) y económicas (paso de secano a regadío) en la agricultura, no ha producido modificaciones sustanciales en el modelo distributivo de éste bien. Por el contrario, el cambio observado, aunque moderado, contribuyó a una mayor polarización de la estructura agraria. Esta evolución ha sido confirmada para un ámbito espacial próximo como es Carmona «entre 1855 y 1910 se han producido ciertas modificaciones en la estructura de la propiedad, modificaciones que ocasionan un mayor desequilibrio en la distribución del suelo?

La mayor separación de la diagonal de la curva de Lorenz — ver gráfico IIen relación a la figura primera, nos indica que los extremos se han ampliado. Además, esto es así en la medida que los propietarios de menos de 20 Has. disminuyen su representación en más de siete puntos en el transcurso de 18941933, mientras que las grandes superficies la aumentan en un 6 por 100. Dos datos ejemplifican mejor aún la tendencia:

a) Un sólo propietraio, D. Ildefonso Marañón Lavín, es dueño del 10,32 por 100 del suelo municipal.

b) El 64,56 por 100 de la tierra es detentada por el 6,1 por 100 de los propietarios mayores de 100 Has.

9. Cruz, J. (1980): Propiedad y... op. cit. pág. 269. 
GRAFICO II. CURVA DE LORENZ 1933

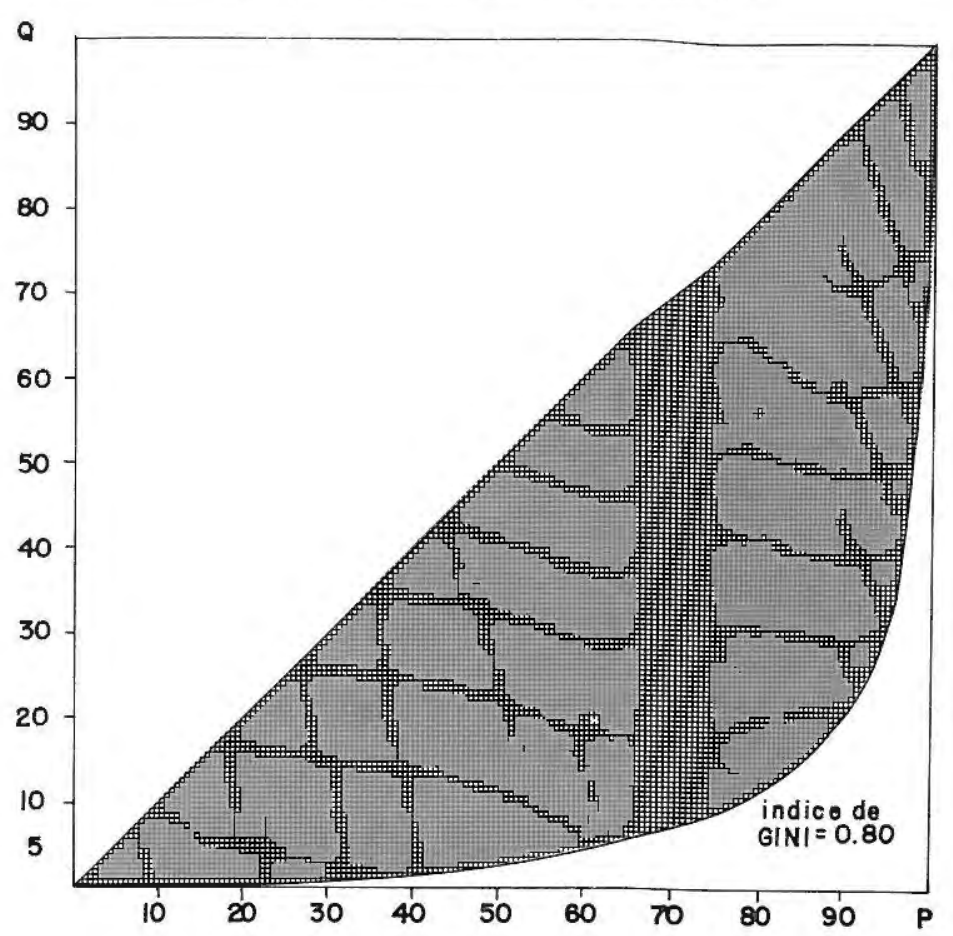

Por su parte, ni el Plan de Riegos de 1902, que tenía como uno de sus objetivos la transformación prioritaria de las tierras de la margen izquierda del Guadaluqivir, si bien sólo afectó al Valle Inferior a partir de 1921, ni el posterior Plan de 1935, incidió, en un primer momento, en la estructura del suelo rústico de Sevilla. Como recoge A. REGUERA ${ }^{10}$, «el gran significado económico de la colonización: la transferencia de grandes cantidades de recursos públicos que se convierten en valor de tierra privatizado», esa plusvalía conla que se encuentran los propietarios la retienen en espera de su mayor explotación especulativa, cuando exista una demanda cierta de tierra que, como veremos, se producirá una vez se «normalice» el país, con parcelaciones y asentamientos de colonos.

El trazado del Canal ha tenido un importante impacto territorial en la medida que añade elementos nuevos y complejiza el enrejado de caminos y vías pecuarias. Junto a piezas menores (pequeños acueductos de obras de fábrica,

10. Reguera, A. (1986): Transformaciones del espacio y política de colonizacion. El bajo Guadalquivir. León. Diputación Provincial. 
sifones,...), la infraestructura de riego más potente, con calados físico que actúan como elemento barrera, rompiendo la continuidad del espacio rústico, están: la carretera de servicio de la zona de riego; las treinta y seis acequias principales y la red de acequias secundarias que distribuyen el riego directamente a las explotaciones.

Toda esa prolija infraestructura, junto con las ayudas y subvenciones oficiales para la transformación de secano-regadío; creación de huertos familiares; construcciones de dependencias y viviendas rurales, electrificación rural... posibilita se materialice, sobre el territorio hispalense, lo que hemos acordado en llamar la primera urbanización del campo, desde lo agrario, como resultado de la intervención pública, (en nombre de la rentabilidad económica privada y el desarrollo), que colabora firmemente a dinamitar las permanencias rústicas y los propios límites rural-urbano.

Producto de la estrategia pública, incentivadora y permisiva para la urbanización del campo desde lo agrario, son los nuevos usos, cuantificados en una superficie de 20,21 Has., de caserio y edificaciones rústicas que ya aparecen recogidos en el Avance del Catastro de 1933.

En cuanto al nivel de parcelación del suelo agrario, a nivel de sistema general de todo el campo hispalense, señalar que:

- Existe un comportamiento inverso entre nivel de parcelación y representación superficial.

- La pequeña parcela (hasta 8 Has.) sólo ocupa el 11,61 por 100 de la superficie censada y, sin embargo, representa casi los $3 / 4-73,30$ por 100 en concreto- del número de parcelas existentes.

- La parcela intermedia o mediana (hasta 64 Has.), ocupa el 36,32 por 100 de la superficie.

- La gran parcela, a partir de las 64 Has., que sólo supone el 5,16 por 100 del total, se extiende por el 52,08 por 100 de la tierra del término municipal.

Con estos datos resulta imposible, por carecer de verosimilitud, concluir que Sevilla haya tenido, hasta 1933 , inclusive, un suelo rústico fragmentado, donde la parcela menuda, pequeña, sea siquiera reseñablemente representativa. La imagen de la Sevilla de huertas - eje nororiental próximo al casco antiguoasociada a un parcelario de escala reducida y numeroso, como hipótesis explicativa sustentada en diversos trabajos de investigación, estamos en condiciones de poder rechazar por no ajustarse a la realidad. 
En cuanto a los usos del suelo, reflejados en el gráfico lll, destaca, además de la presencia de superficies de riesgo, el aumento relativo del olivar, el surgir de la masa arbórea, a niveles estadísticos, - eucaliptos y árboles de ribera-, el retroceso de la superficie de huertas y la desaparición del cultivo de viñedo. En la amplia ocupación $(14,27$ por 100$)$ de improductivo se engloba, además, el suelo edificado y zonas de ocio como parques e hipódromo.

GRAFICO III. USOS DE LA TIERRA EN 1933

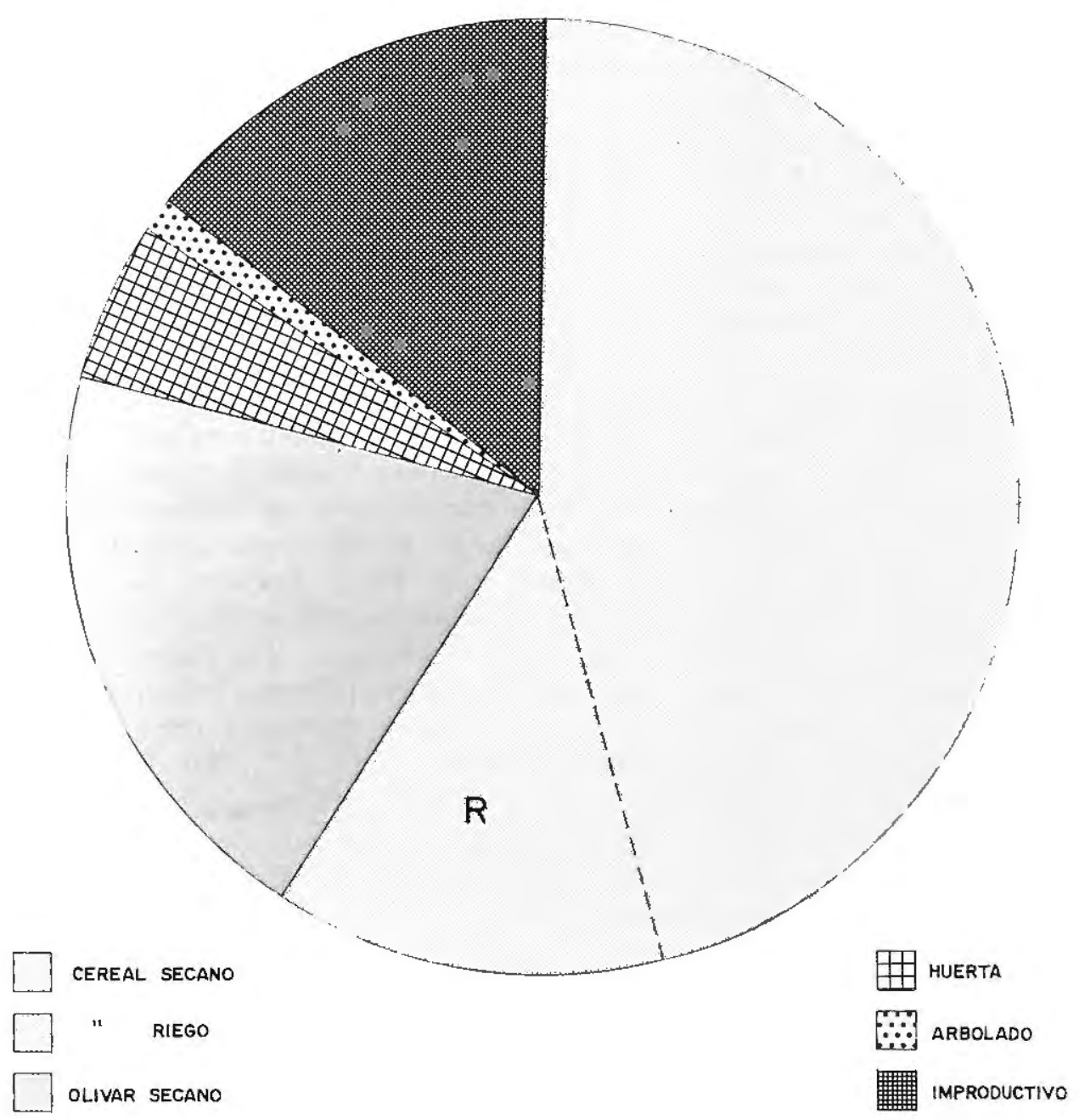




\section{EL CAMPO SEVILLANO A MEDIADOS DEL SIGLO XX}

Los acontecimientos, no sólo propiamente rurales sino también de expectativas urbanas, desarrollados en los quince años que separan 1933 de 1948 modifican más la estructura agraria de Sevilla que el medio siglo transcurrido desde 1872 a 1933.

La tensión social que genera la proclamación de la $2 .^{a}$ República -con una asignatura pendiente como era la Reforma Agraria - en una Ciudad básicamente rural y con importantes desigualdades, consecuencia de la excesiva concentración de la propiedad, junto a una gran tradición reivindicativa en las capas de los desheredados, suscita la posibilidad, en los propietarios, de ser desposeídos y, por ende, se planteen vender parte de su patrimonio.

Por otra parte, la capitalización de las tierras a que dió lugar la puesta en riego del Valle Inferior en los años veinte y treinta, junto a la victoria nacional en la guerra civil que viene a representar, para el cuerpo social, el triunfo de la propiedad privada y de la economía de libre mercado sobre un modelo social igualitario y progresista representado por la República, puede de nuevo volver a estabilizar la estructura agraria y, explica sin duda, «los altos precios agrícolas que tuvieron lugar inmediatamente después de la guerra», según M. DRAIN ${ }^{11}$.

De cualquier forma, y desde una perspectiva global del sistema territorial Campo/Ciudad, podemos afirmar que son las actividades y usos urbanos y la ampliación de sus escalas, justificado por la concentración de la población y fundamentado por el planeamiento, en cuanto asignador de localizaciones, las que modifican la estructura agraria secular de Sevilla. Como acertadamente sintetiza G. FONSECA ${ }^{12}$, «en el contexto español de la posguerra, la atención que se prestaba al medio rural desde las instituciones urbanísticas oficiales estuvo estimulada por el ruralismo imperante. En los años de la autarquía franquista... sus premisas eran la consideración del campo como posible zona de extensión de la Ciudad por lo que no se planteaban problemas agronómicos».

De estas últimas palabras Sevilla es un paradigma singular. Desde lo urbano, el territorio municpal ha sido entendido como extensión inorgánica de la Ciudad. ¿Y desde lo rústico?: preparación del Campo para que el modelo urbano, ya dominante como creador de plusvalías, se facilite y consolide. Esta tesis la apoyamos en los siguientes hechos:

11. Drain, M. (1977): Les Campagnes de la province de Sevilla. Espace agricole et sociète rurale. Lille. Atelier Reproduction de Theses, 2 Vols.

12. Fonseca, G. (1940): Colonización evolutiva. Madrid. I Congreso de la Federación de Urbanismo y de la Vivienda. 
a) Desmenuzamiento del suelo rústico.

b) Aumento de los elementos constructivos y edificatorios en el campo.

c) Difuminación de las preexistencias rurales (caminos y vías pecuarias).

b) Modificación de los usos agrarios.

En el período 1933-1948 la parcelación ha crecido un 35 por 100. Y, en concreto, las parcelas inferiores a 2 Has. lo han hecho en un 50 por 100 .

Caserio y edificaciones rústicas han aumentado su representación superficial en una relación 13 a 1.

Dentro de una tendencia parcelaria, a nivel de todo el término municipal, que camina hacia una mayor polarización (la desagregación afecta a las pequeñas fincas -menores de 8 Has.- mientras que las grandes - superiores a 64 Has.- sufren incluso un leve proceso de concentración), el tratamiento zonal del fenómeno nos permite hacer algunas puntualizaciones:

1) La mayor relación parcela/superficie, de forma muy destacada, se encuentra en la zona meridional del término municipal y afecta al grupo de explotaciones de menor tamaño (de 0 a 8 Has.), lo cual nos indica que ha sido el área más intervenida urbanísticamente (localización de la Exposición Iberoamericana de 1929).

2) Por lo escasamente antropizado del área noroccidental, sus valores hay que entenderlo dentro del contexto puramente rural, dominado por la gran parcela - cortijo de Gambogaz- y la extensa propiedad.

3) En cuanto al dominio cuantitativo poligonal de las parcelas menores de 8 Has. - no así del significado superficial de las mismas - se sitúan, si bien de forma no tan contundente sino quebrada, con la zona de la primera periferia urbana.

Pero sin que nos desviemos de nuestro objetivo en éste artículo, la estructura agraria en 1945-1948 refleja una significativa erosión de las grandes propiedades, recogido fielmente ese mayor equilibrio en la curva de Lorenz (gráfico IV) y sentenciado por el valor 0,72 del índice de Gini.

Un dato que no recoge la estructura del suelo es la titularidad del mismo. El Catastro nos confirma que el suelo público ha llegado a representar un cuarto del total municipal. Instalaciones de Defensa y Aeropuerto; empresas públicas como Campsa, Unión Española de Explosivos...; Escuela de capacitación agraria y finca gestionada por Diputación (cortijo de Cuarto), constituyen los usos mayoritarios. El suelo público local asciende a 214,14 Has. 
GRAFICO IV. CURVA DE LORENZ 1945-48

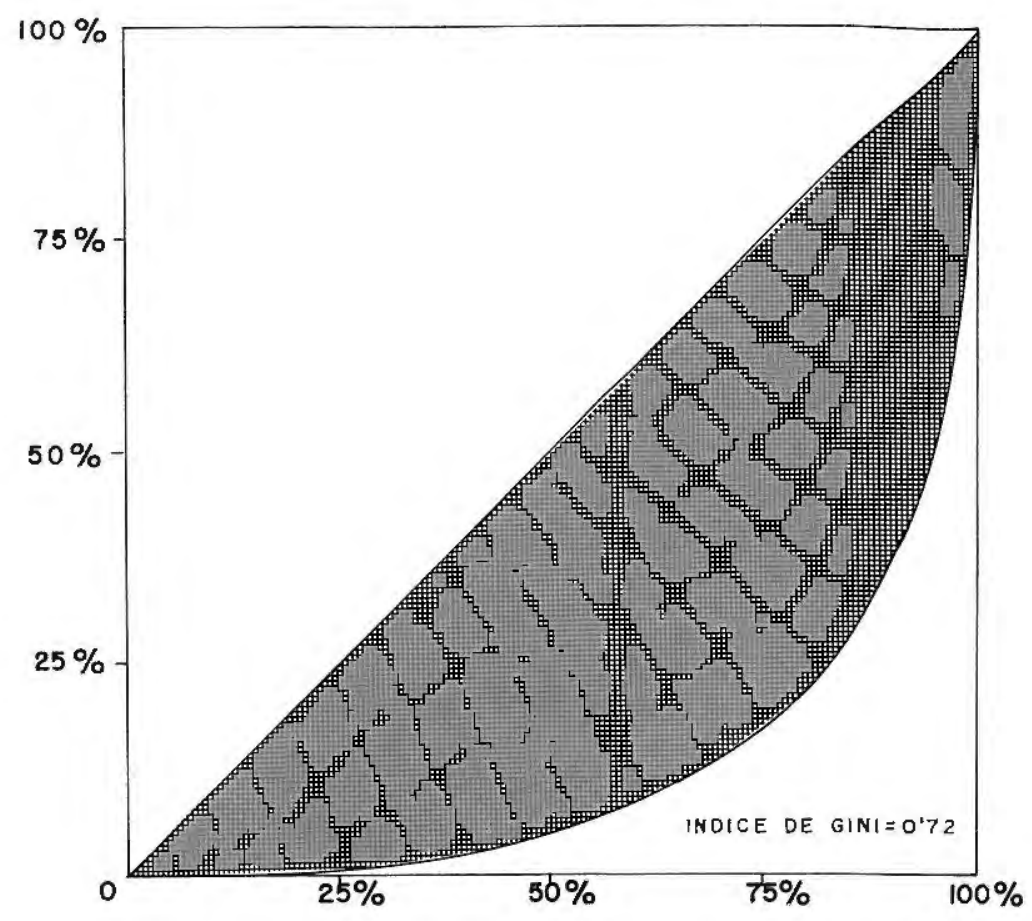

Una aclaración respecto a la distribución de la propiedad es que si bien los propietarios de fincas (superficie bajo unos mismos límites) mayores de 100 Has. ha descendido a dieciocho personas, el que se dé la práctica habitual de que un mismo propietario tenga más de una finca en el término municipal, eleva a veintitrés el número de grandes propietarios. El gráfico $\mathrm{V}$ recoge la evolución de las grandes propiedades desde 1872 a 1945-1948 en el que se acusa notablemente el descenso, en el último escalón cronológico, del latifundio local.

El modelo de división de las grandes fincas, desde lo urbano, del que ponemos un ejemplo gráfico en la figura I, se ha caracterizado en ésta etapa por:

a) El geometrismo de las parcelas resultantes, muy dependiente del medio físico.

b) Se crean parcelas alargadas de amplio fondo y apoyadas en los elementos estructurales del territorio - caminos, arroyos...-. 


\section{GRAFICO $V$.}

REPRESENTACION DE LAS GRANDES PROPIEDADES ( $>$ DE 100 HA.) RESPECTO AL TOTAL DE LA SUPERFICIE

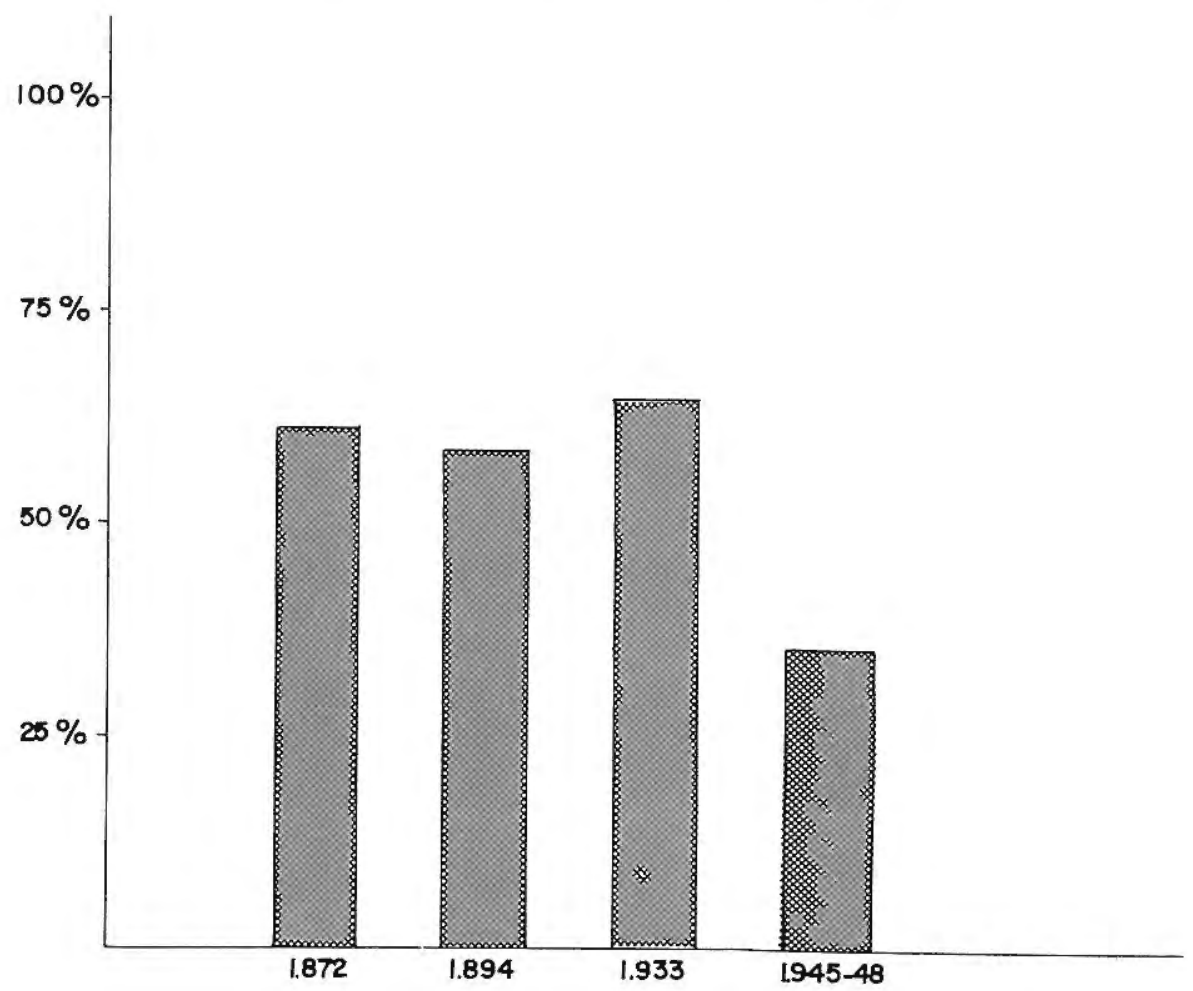

c) Se suele parcelar, para su venta posterior, una parte de la explotación, quedándose el propietario con la mayor parte en espera de ver crecer su valor una vez las pequeñas parcelas hayan sido ocupadas, pronto, por una vivienda autoconstruida.

Desde lo rústico, los diversos modelos de organización de las explotaciones agrarias, detectados en los croquis y planos catastrales, sobresalen las siguientes premisas:

- Los modelos individualizados se solapan y repiten, a veces, en un mismo espacio. Esto es, una gran explotación o propiedad soporta diversas formas de organización. 


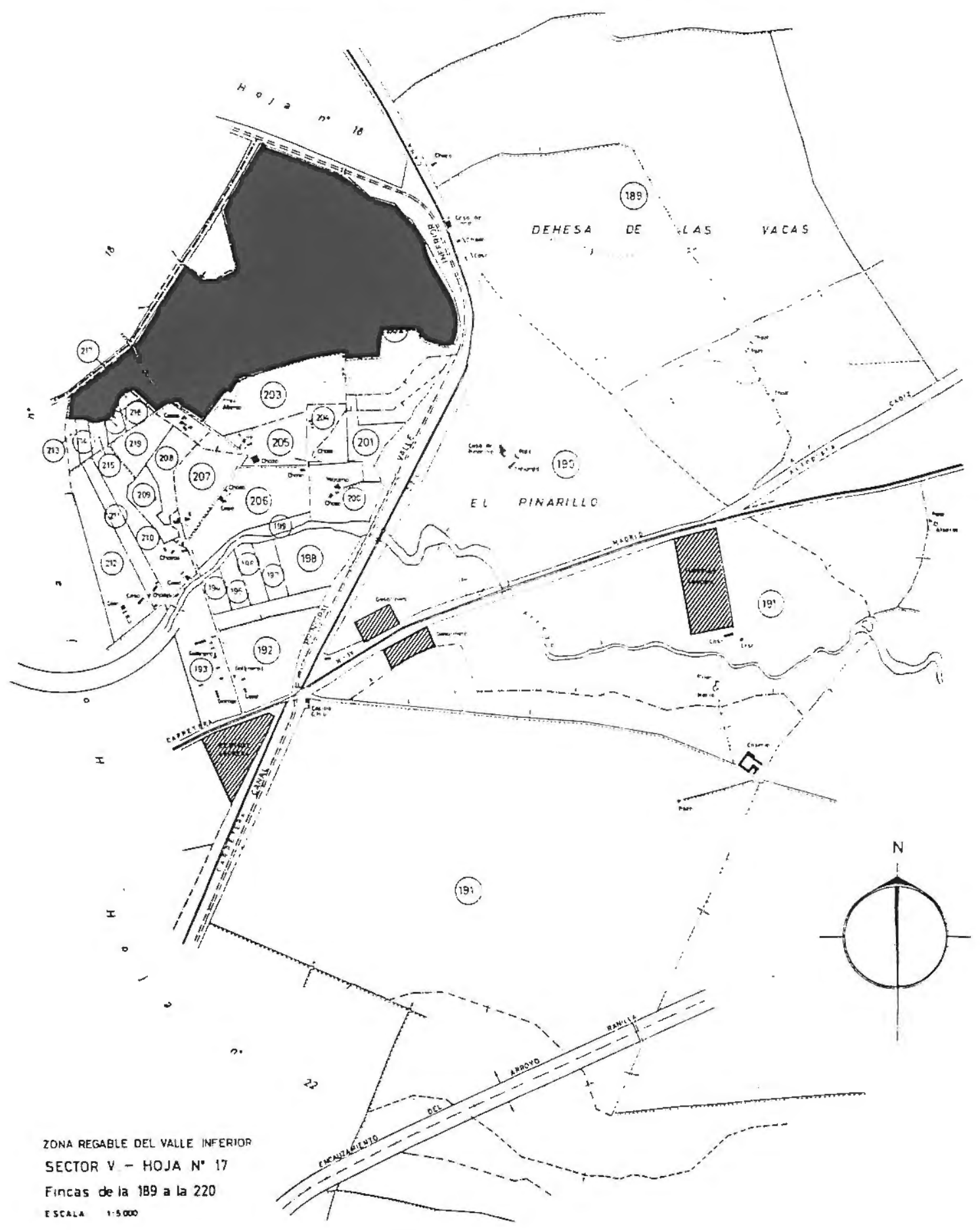


- Se trata de subsistemas (los modelos) dinámicos que aparecen, se desarrollan transformándose y desaparecen por la práctica social de utilización del suelo. Prueba de ello es que los tres modelos acotados en el Avance del Catastro en 1933 (modelo de grandes piezas parcelarias; modelo agrícola extensivo y modelo de pequeñas piezas) se amplian, en dos nuevos, para cuando se realiza, quince años más tarde, el Catastro de 1945-1948, a saber (modelo agrícola intensivo y modelo de vías pecuarias).

En síntesis, todo el entramado alógeno y reciente que incorpora tanto la infraestructura de riego como la propia potenciación de los elementos urbanizadores del campo, añadido al modelo de operar en la parcelación para usos residenciales, caracterizado por el geometrismo y rectangularidad de las unidades parcelarias resultantes, está dando lugar a un escenario territorial puenteado, explosivo, desde el punto de vista físico, de las pertenencias y permanencias autóctonas del suelo rústico, que se potencia y consolida por la práctica mercantil del propietario del suelo y la inactividad cautelar de la Administración.

En cuanto a los usos, gráfico VI, es de destacar: el notable aumento de la superficie de riego; prosigue el olivar en extensión mientras que el cereal disminuye un 6 por 100, en relación a 1933. Los usos urbanos que esconde el apartado «improductivo» crecen, a niveles absolutos, en setenta y unas Has. y, lo que es más relevante para explicar, a partir de esta fecha, uno de los aspectos de la invasión/colonización del campo por la ciudad: la valoración cuantitativa y la reutilización de los ejes primarios vertebradores del territorio; ello pertenece a otra fase del análisis en realización.

\section{CONCLUSIONES}

Con excesiva frecuencia se olvida no sólo que el campo antecede a la ciudad sino incluso que ésta se asienta sobre aquél. De otra manera, se trata de dos subsistemas paralelos pero excluyentes tal como han sido planteados por la práctica. La presencia de uno anula al otro en las grandes conurbaciones, imponiéndose el más dinámico y rentable — la Ciudad - sobre el más estático y lento en la reproducción económica —el Campo-. No puede ser de otro modo en un mundo de relaciones productivas - entre las que se debe incluir la generación de los espacios funcionales - dominada por la eficacia y el máximo beneficio que, a cambio, «soporta» el desequilibrio como constante principal. Desequilibrio rústico que se transmitirá a lo urbano como fase más desarrollada del sistema. 
GRAFICO VI. USOS DE LA TIERRA EN 1945-48

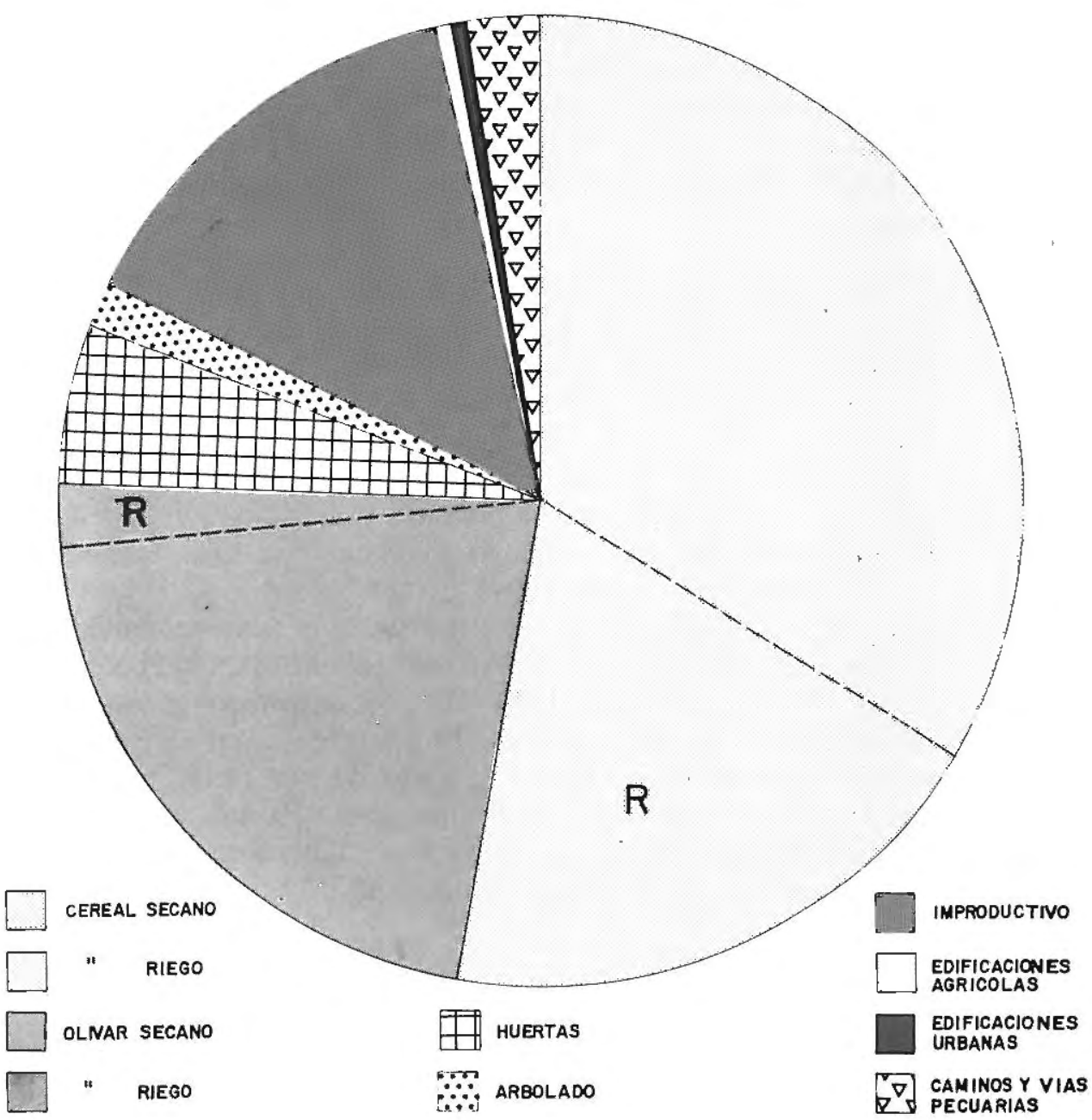

La propiedad y su materialización física que es la explotación o finca, símbolos identificadores y justificadores de una clase social y de una forma de vida, estan dispuestos a perecer a cambio de un mayor poder económico. Una estructura rústica, prácticamente invariable desde mediados del siglo XIX a mediados del XX, se aprovecha de sus potencialidades favorables - fuerte concentración de la propiedad; capitalización de sus predios de forma casi gratuita gracias al sector público (transformación secano-regadío); demanda de suelo como consecuencia del comienzo de la concentración urbana; facilidades 
para la división y subdivisión parcelaria,... - para ir desmantelándose de la forma más rentable y generando, a su vez, un mercado especialmente imperfecto.

El cambio pendiente para completar el ciclo (el de los usos), se consolidará en las décadas posteriores como corresponde a una sociedad local tardodesarrollada.

\section{BIBLIOGRAFIA}

ARTOLA, M. y otros (1978): El latifundio. Propiedad y explotación, ss. XVIII-XX. Madrid. Ministerio de Agricultura.

CRUZ, J. (1980): Propiedad y usos de la tierra en la Baja Andalucía. Carmona, siglos XVIII-XX. Madrid. Ministerio de Agricultura.

DRAIN, M. (1977): Les Campagnes de la province de Sevilla. Espace agricole et societe rurale. Lille. Atelier Reproduction de Theses, 2 Vols.

FONSECA, G. (1940): Colonización evolutiva, en Varios (1988). Políticas y Técnicas en la Ordenación del Espacio Rural, Madrid. Ministerio de Agricultura.

HERAN, F. (1980): Tierra y parentesco en el campo sevillano: la revolución agrícola del siglo XIX. Madrid. Ministerio de Agricultura.

LAZO, A. (1970): La desamortización de las tierras de la Iglesia en la provincia de Sevilla. Diputación Provincial.

PARIAS, M.: Aproximación a la tipología del propietario agrícola andaluz en el siglo XIX. Ocho casos de inversión sevillana. Rev. Estudios Andaluces, n. ${ }^{\circ}$ 10, 1988, pp. 137-176.

REGUERA, A. (1986): Transformaciones del espacio y política de colonización. El bajo Guadalquivir. León. Diputación Provincial. 